\title{
A aquisição pública de alimentos como mecanismo de desenvolvimento na Colômbia
}

\author{
Sergio Schneider \\ Universidade Federal do Rio Grande do Sul - Porto Alegre - Rio Grande do Sul - \\ Brasil \\ Nathalia Valderrama Bohórquez \\ Universidade Federal do Rio Grande do Sul - Porto Alegre - Rio Grande do Sul - \\ Brasil
}

\begin{abstract}
Resumo
A alimentação pública é um campo em disputa, em que os atores coletivos, por meio das suas habilidades sociais, reconstroem normas e significados para conduzir à emergência ou à estabilidade da política. O objetivo do estudo é analisar como a aquisição pública de alimentos pode ser um mecanismo de desenvolvimento em zonas de conflito armado na Colômbia, empregando a perspectiva da Teoria dos Campos de Ação Estratégica e a Abordagem Possibilista de Albert Hirschman. Metodologicamente, a pesquisa corresponde a três estudos de caso. Analisam-se como as formas de organização social de atores coletivos disputam concepções de mundos, redefinem regras e normas e empregam múltiplos recursos para formar alianças, desestabilizar o campo, consolidar seus interesses e reproduzirem-se socialmente. Os resultados sugerem que as políticas públicas de alimentação são concebidas sob estruturas homogêneas que ignoram e tornam invisíveis as formas de gestão comunitária e autônoma. A gestão comunitária e autônoma resiste aos modelos homogeneizadores da contratação pública e do abastecimento, e reivindica a necessidade de redefinir as regras e concepções de mundos em relação a qualidade e as relações que transcendem do campo econômico. Essa última expressa-se como forma de organização mais eficiente e eficaz na resposta às demandas prioritárias das populações rurais. Além disso, constrói novos significados em torno da qualidade dos alimentos e da gestão dos programas públicos em alimentação, num processo de disputas pela reprodução dos múltiplos atores dentro do campo.

Palavras-Chave: Teoria dos Campos de Ação Estratégica. Albert Hirschman. Conflito armado. Políticas públicas de alimentação.
\end{abstract}

\section{The public acquisition of food as mechanism of development in Colombia}

\section{Abstract}

Public feeding is a struggled field where collective actors, through their social skills, reconstruct norms and meanings to lead the emergence or stability of the politic. The objective of this study is to analyse how the public acquisition of food can be a mechanism of development in armed conflict zones in Colombia from the perspective of the Theory of 
Strategic Action Fields (SAFs) and from the possibilism approach by Albert Hirschman. Methodologically, the research corresponds to three case studies. Specifically, the forms of community and autonomous management are analysed as the modes of social organization of collective actors dispute conceptions of life-worlds, redefine rules and norms, and use multiple resources to form alliances, destabilize the field, consolidate their interests and reproduce socially. The results suggest that public policies of food are conceived under homogeneous structures that ignore and render invisible the forms of community and autonomous management. The community and autonomous management resists the homogenizing models of public procurement and supplying, and claims the necessity to redefine the rules and conceptions of the life-worlds in relation to quality and relationships that transcend the economic field. This is expressed as a more efficient and effective form of organization in response to the priority demands of rural populations. Likewise, it builds new meanings around the quality of food and the management of public feeding programs in a process of struggles for the reproduction of the multiple actors within the field.

Keywords: Theory of Strategic Action Fields (SAFs). Albert Hirschman. Armed conflict. Public feeding policies.

\section{La adquisición pública de alimentos como mecanismo de desarrollo en Colombia}

\section{Resumen}

La alimentación pública es un campo en disputa donde los actores colectivos a través de sus habilidades sociales reconstruyen normas y significados para conducir la emergencia o la estabilidad de la política. El objetivo del estudio es analizar como la adquisición pública de alimentos pueden ser un mecanismo de desarrollo en zonas de conflicto armado en Colombia desde la perspectiva de la Teoría de los Campos de Acción Estratégica y desde el abordaje posibilista de Albert Hirschman. Metodológicamente, la investigación corresponde a tres estudios de caso. Específicamente, se analizan las formas de organización social de actores colectivos que disputan concepciones de mundos, redefinen reglas y normas, y emplean múltiplos recursos para formar alianzas, desestabilizar el campo, consolidar sus intereses y reproducirse socialmente. Los resultados apuntan que las políticas públicas de alimentación son concebidas bajo estructuras homogéneas que ignoran y tornan invisibles las formas de gestión comunitaria y autónoma. La gestión comunitaria y autónoma resiste a los modelos homogeneizadores de la contratación pública y del abastecimiento y revindica la necesidad de redefinir las reglas y las concepciones de mundos en relación con la calidad y las relaciones que transcienden del campo económico. Esa última se expresa como forma de organización más eficiente y eficaz en respuesta a las demandas prioritarias de las poblaciones rurales. Así mismo, construye nuevos significados en torno a la calidad de los alimentos y a la gestión de los programas públicos en alimentación en un proceso de disputas por .la reproducción de los múltiples actores dentro del campo.

Palabras-Clave: Teoría de los Campos de Acción Estratégica. Albert Hirschman. Conflicto armado. Políticas públicas de alimentación.

\section{Introdução}

As aquisições públicas de alimentos tornaram-se importantes para os processos de desenvolvimento, especialmente em países de desenvolvimento tardio e com conflitos sociais nas zonas rurais. Estudos tem mostrado que isso ocorre quando governantes inclinam-se a gerir o Estado de tal sorte a propiciar processos de coesão social, por meio de estratégias que vinculem a proteção social e as dinâmicas produtivas, mas também contrabalanceando o jogo de forças e poder para 
permitir a vinculação dos produtores dentro dos programas públicos de alimentação (SUMBERG e SABATES-WHEELER, 2011).

Segundo o Programa Mundial de Alimentos (PMA), a criação e gestão de mercados institucionais através do mecanismo das compras públicas, também chamado de "prato público", pode fomentar a transferência de recursos a partir do Estado e favorecer processos distributivos, auxiliando as comunidades rurais na superação da pobreza, na redução das vulnerabilidades, na melhoraria do empoderamento e da organização social, assim como contribuir para a permanência e a reprodução das famílias agricultoras no meio rural (PMA, 2012). Estudos do PMA tem mostrado que alimentação pública, pode ser um potencial aliado para vincular as estratégias de nutrição de populações desfavorecidas à dinâmicas regionais de desenvolvimento.

A compra de produtos alimentares nos locais em que são produzidos tende a melhorar a condição nutricional das populações fazendo com que o acesso aos alimentos impacte na redução da pobreza e da fome (PMA, 2013). Além disso, políticas de aquisição alimentares podem ser um mecanismo para incrementar a qualidade dos alimentos incentivando a compra de produtos orgânicos e agroecológicos, o que pode melhorar a eficiência e inclusive reduzir o gasto público. Mas as compras públicas também podem contribuir para criar e melhor os hábitos alimentares saudáveis e melhorar os laços sociais entre os produtores e os consumidores. Por fim, não menos importante, o PMA tem mostrado que as compras públicas podem ser um mercado estável para os agricultores através do fomento à redes institucionais para o combate à subnutrição (PMA, 2015).

O processo de compra governamentais também é importante para criação e fomento aos chamados mercados institucionais, que são mecanismos que se utilizam do poder de compra do Estado para estabelecer programas de alimentação pública que visam promover ações de inclusão social e produtiva de beneficiários individuais, grupos sociais ou comunidades locais menos favorecidas (MORGAN e SONNINO, 2008). Os mercados institucionais podem ser entendidos como espaços de construção social, em que é possível equilibrar as relações de poder dentro dos sistemas agroalimentares.

Segundo Morgan e Sonnino (2008), a política de aquisição de alimentos é um mecanismo poderoso para a construção de uma sociedade sustentável e progressiva, ao criar oportunidades de desenvolvimento para produtores de alimentos agroecológicos, em pequena escala e do comércio justo, ao mesmo tempo que permite o acesso a alimentos mais frescos, de melhor qualidade e que reconhece a cultura alimentar das comunidades. Vários estudos têm analisado as múltiplas vantagens da compra direta de alimentos nos programas de alimentação públicos, tanto na dinamização das economias produtivas familiares quanto na qualidade da alimentação (BARBOSA-GONÇALVES et al., 2015; BUCKLEY et al., 2013; CONSTANTY e ZONIN, 2016; DEVEREUX et al. 2008; GELLI e SUWA, 2014; MASSET e GELLI, 2013; SIDANER et al., 2013; WITTMAN e BLESH, 2017).

As experiências desenvolvidas internacionalmente evidenciam as potencialidades que os mercados institucionais têm para o fornecimento de alimentos a partir da diversificação produtiva, incluindo a promoção da agroecologia e os alimentos orgânicos (ARUMUGAM, 2015; FOEKEN et al., 2010; MIKKELSEN et al., 2006; MORGAN; MORLEY, 2002). 
No Brasil, a formulação e a implementação de políticas públicas que integram circuitos curtos em sistemas alimentares descentralizados, em alguns casos têm sido capaz de promover formatos de produção sustentáveis e de base agroecológica (BLESH; WITTMAN, 2015; CONSTANTY e ZONIN, 2016; INTERNATIONAL FOOD POLICY RESEARCH INSTITUTE, 2015; SILVERIO; SOUSA, 2014). Segundo MALUF et al. (2015) estes casos permitem o acesso a dietas mais saudáveis e diversificadas, a redução das perdas e desperdícios e a redução dos custos energéticos, de transporte e logísticos.

No entanto, existem desafios, sobretudo os impostos pelas normas sanitárias e às legislações de aquisição, que criam barreiras a participação direta dos agricultores, especialmente os familiares, que são justamente os que mais demandam este tipo de apoio (OLIVEIRA, 2017; SIDANER et al., 2013; SILVEIRO e SOUSA, 2014; SIOBHAN e SWENSSON, 2017).

Neste artigo pretendemos refletir sobre a questão do potencial das compras públicas tomando como pano de fundo o caso da formação de redes agroalimentares de aquisição de alimentos em zonas de conflito armado da Colômbia. O estudo analisará como a aquisição pública de alimentos pode-se constituir em um mecanismo de desenvolvimento em zonas de conflito armado a partir das referências encontradas na teoria dos campos de ação estratégica, formulada por Fligstein e McAdam, complementada com "insights" extraídos da abordagem possibilista do Albert Hirschman. Para elaborar nossa análise, buscaremos identificar os processos de disputa dos quadros normativos, dos recursos e dos significados que influenciam constantemente nas transformações dos programas de alimentação pública na Colômbia. A relevância do artigo fundamenta-se nas contribuições que traz aos debates da alimentação pública como mecanismo de desenvolvimento. Vale ressaltar que este artigo é parte de uma pesquisa mais ampla sobre estratégias alimentares na Colômbia.

Para desemaranhar as complexas relações da alimentação pública na Colômbia, propõe-se uma análise histórica das transformações dos principais programas de alimentação: os programas de alimentação do Instituto Colombiano de Bienestar Familiar (ICBF) e do Programa de Alimentação Escolar (PAE).

Três estudos de caso foram realizados nos municípios de Granada (Antioquia), Samaniego (Nariño) e Florencia (Caquetá). As unidades de análise foram o Programa de Alimentaçión Escolar (PAE) e os Programas do Instituto Colombiano de Bienestar Familiar (ICBF). Os municípios foram escolhidos para a amostra considerando como critério o grau de afetação pelo conflito armado. A amostra é um recorte significativo para analisar as transformações dos programas públicos de alimentação em zonas de conflito armado.

A pesquisa de campo ocorreu entre 1 de fevereiro e 30 abril de 2018. A permanência nas regiões pesquisadas foi de: 21 dias em Nariño, 18 dias em Caquetá e 26 dias em Antioquia. O período foi definido por um cronograma planejado com antecedência e modificado conforme $o$ avanço do trabalho de campo. Adicionalmente, foram consultados documentos oficiais, publicações e relatórios.

Foram aplicadas quatro técnicas de coleta dos dados: consulta em bases de dados estatísticos, análise documental (documentos da Biblioteca Luís Angel Arango em Bogotá e bibliotecas locais nos municípios estudados), entrevistas semiestruturadas, observação participante e diário de campo. No total, foram realizadas 50 entrevistas semiestruturadas com camponeses, professores, mães 
comunitárias ${ }^{1}$, funcionários públicos e técnicos de ONGs. A escolha dos participantes foi realizada empregando a técnica de snowball². Indagou-se, especialmente, sobre as mudanças na forma de aplicação dos recursos dos programas, nas formas de contratação, na procedência e qualidade dos alimentos, assim como o contexto da alimentação e da agricultura durante a violência armada3.

Os resultados foram organizados para análise usando o NVIVO Starter 11 e os indicadores escolhidos foram a trajetória histórica dos programas de alimentação pública, as redes agroalimentares nas zonas de conflito armado e as formas de gestão do prato público.

O artigo organiza-se em cinco seções, além dessa introdução. A segunda apresenta o referencial teórico, a terceira seção contextualiza o caso da alimentação pública e o conflito armado na Colômbia. A quarta aprofunda nos três elementos mais disputados na alimentação pública: a qualidade, a eficiência e a racionalidade do gasto público. Já a quinta seção apresenta os recursos e as formas de organização autônoma e comunitária que desafiam os quadros normativos existentes. Por fim, são apresentadas as considerações finais do estudo.

\section{0 prato público no contexto do conflito armado Colombiano}

Colômbia é um país que atualmente possui uma população total de 49.834.240 habitantes, sendo o segundo mais populoso da América do Sul. Os municípios considerados rurais correspondem a $75 \%$ do total e retêm cerca de $30 \%$ da população. No entanto, o rural colombiano encara grandes desafios em relação ao acesso limitado a serviços, infraestrutura precária e ausência de políticas públicas democráticas (DANE, 2016; DNP, 2015; PNUD, 2011). A taxa de frequência escolar no grupo populacional de 5 aos 24 anos é de 65,5\% (DANE, 2005). O número total de matriculados em educação formal, em 2017, foram 10.020.294 pessoas. No entanto, a cobertura da alimentação escolar atingiu só 4.716.299 destas, representando um estimativo de aportes de $\$ 1,8$ bilhões de pesos colombianos (aproximadamente USD 561 milhões de dólares) (TELLEZ, 2018).

Na Colômbia, o prato público tem sido apropriado por empresas do setor privada que desconhecem ou desconsideram as dinâmicas sociais e produtivas das comunidades rurais assim como seu potencial. Nas décadas 1970 e 1980 o abastecimento público prato público transitou de uma concepção paternalista para uma comunitária. Isto é, o Estado reconheceu a importância da gestão dos grupos associativos e cooperativas como grupos solidários, lojas comunitárias, microempresas, grupos familiares e organizações de fato, os quais aumentaram a cobertura e reduziram os custos (URIBE,1988). No entanto, a partir dos anos $1990 \mathrm{e}$ intensamente nos últimos anos, a implementação de modelos excludentes tem

\footnotetext{
${ }^{1}$ As mães comunitárias é a figura coletiva que tem as suas origens antes dos anos 1970. Oficialmente a partir dessa década, essa figura foi reconhecidas oficialmente dentro do programa de Hogares Comunitarios de Bienestar (HCB) do Instituto Colombiano de Bienestar Familiar (ICBF). As mães num começo se ofereciam voluntariamente para receber e cuidar nas suas próprias casas aos filhos das famílias vizinhas e recebiam do Estado o suporte econômico de uma bolsa (de muito baixo valor econômico) em troca do serviço prestado a comunidade (URIBE, 1988).

${ }^{2}$ Essa técnica permite seguir a rede de atores-chave que participam e agenciam os processos sociais estudados nessa pesquisa por referência dos interlocutores inicialmente entrevistados ou abordados.

3 Porém, o acordo de paz foi assinado no 26 de setembro de 2016 entre a guerrilha das Forças Armadas Revolucionárias da Colômbia- Exército do Povo (FARC-EP), Devido à complexidade do conflito na Colômbia, a violência armada ainda persiste em alguns lugares do país, como se explica na seguinte seção do artigo.
} 
mudado as dinâmicas da prestação do serviço, excluindo diretamente às organizações comunitárias, anulando e deslegitimando a sua capacidade de empregar recursos materiais e humanos disponíveis, aumentando os custos de operação e, consequentemente, reduzindo a qualidade do serviço nas mãos dos operadores privados (BERNAL, 2014; FAO, 2013).

Depois de mais de seis décadas de conflito interno e com estatísticas alarmantes em relação à violência, o país procura construir caminhos para a construção de uma paz estável e duradoura, especialmente nas zonas rurais. Nesse sentido, o abastecimento dos mercados institucionais com produtos locais está previsto no acordo de paz, especificamente no ponto 1 da Reforma Rural Integral, assinado pelo governo nacional e pela guerrilha Forças Armadas Revolucionárias de Colômbia- Exército do Povo (FARC-EP), no ano de 2016.

Os debates sobre os mercados institucionais têm ecoado em três espaços importantes de forma transversal em nível nacional. Em primeiro lugar, em 2017, criou-se o Sistema para a Garantía Progresiva del Derecho a la Alimentación que propõe ser participativo e integrar os diferentes níveis e setores do Estado em Conselhos Estaduais e Municipais, com participação de delegados da sociedade civil. Em segundo lugar, durante o ano 2017, a Mesa Técnica de Agricultura Familiar y Economía Campesina fomentou espaços de discussão e coletou aportes que possibilitaram a criação das Diretrizes Estratégicas de Política Pública para a Agricultura Camponesa, Familiar e Comunitária, que inclui as compras públicas locais agroalimentares no item 6.1. Essas diretrizes serviram de referência à Resolução 464 de 2017 do Ministerio de Agricultura y Desarrollo Rural4. Finalmente, desde 2017 conformou-se a Mesa de Compras Públicas liderada pela Unidad Administrativa Especial de Organizaciones Solidarias do Ministério de Trabalho. Essa Mesa teve a iniciativa de reunir elementos para formular o Projeto de Lei de Compras Públicas, atualmente aprovado para debate na Comissão Quinta da Câmara de Representantes da Colômbia, que poderá conduzir à formalização da compra direta de produtos das organizações camponesas, familiares e comunitárias.

Nesse contexto, é importante esclarecer que os fenômenos de violência têm sido vivenciados de formas heterogêneas nos municípios estudados. A Tabela 1 apresenta o número de casos de violência para essas regiões desde 1958 até 2018. Para conhecimento do leitor, o município de Granada localiza-se no Leste Antioqueño, Samaniego no Oeste de Nariño e Florencia corresponde a região da capital do Estado de Caquetá e arredores.

\footnotetext{
${ }^{4}$ Essa Resolução tem como objetivo orientar a planificação e a gestão da ação do Estado nos princípios do desenvolvimento rural com enfoque territorial. Ela visa o bem-estar das comunidades do campo e o melhoramento da sustentabilidade da produção agropecuária.
} 
Tabela 1. Número de casos de violência nas regiões estudadas

\begin{tabular}{lcccc}
\hline Tipo de Violência & Este Antioqueño & Oeste de Nariño & $\begin{array}{c}\text { Florencia } \\
\text { arredores }\end{array}$ & $\begin{array}{c}\text { Total } \\
\text { Nacional }\end{array}$ \\
\hline Ações de guerra & 1.029 & 176 & 1.066 & 34.897 \\
Assassinatos seletivos & 7.120 & 127 & 3.137 & 51.563 \\
Ataques a populações & 15 & 8 & 8 & 488 \\
Atentados terroristas & 10 & 3 & 6 & 238 \\
Desaparecimento & 2.444 & 142 & 1.996 & 68.431 \\
forçado & & & & 8.952 \\
Minas e explosivos & 552 & 221 & 346 & 4.210 \\
Massacres & 214 & 6 & 65 & 31.021 \\
Sequestro & 2.448 & 131 & 704 & 15.222 \\
Violência sexual & 772 & 55 & 488 & 20.870 \\
Danos a bens & 1.114 & 87 & 287 & 16.894 \\
Recrutamento & 377 & 42 & 591 & \\
\hline
\end{tabular}

Fonte: CNMH e OMC (2018).

Os fenômenos de violência em Granada relacionam-se, principalmente, com a reprodução das guerrilhas das FARC e do Exército de Libertação Nacional (ELN) nos municípios da região e com as táticas militares de luta contra os grupos subversivos, assim como com a sua localização estratégica sobre a estrada que liga Medellín e Bogotá e com os projetos hidroelétricos na região. Num primeiro momento, de 1980 a 1996, primava a hegemonia guerrilheira. Posteriormente, de 1997 a 2004, o fortalecimento dos grupos paramilitares e a força das táticas contra os subversivos acirraram o conflito armado na região. A população tornou-se estigmatizada e ameaçada, ficando no meio do fogo cruzado e da disputa pelo poder dos grupos armados. Finalmente, após o ano 2005, na região houve uma retirada das tropas militares e a desmobilização dos paramilitares, especificamente do Bloque Cacique Nutibara (CNMH, 2016a).

Já em Samaniego, os fenômenos acirrados de violência armada foram um pouco mais recentes e a situação de insegurança persiste. Desde os anos 1980, surgiram os grupos armados Guerrilleros Comuneros de Sur, Compañía Guerreros del Sindagua e Mártires de Barbacoas pertencentes ao ELN e o Frente 29 e Columna Mariscal Sucre ligados às FARC. A partir dos anos 2000, surgiram o Bloque Central Bolívar e Libertadores del Sur das Autodefesas Unidas de Colômbia (AUC) (LLAMAMIENTO DE GINEBRA, s.d.). A sua aparição na região está relacionada com a ampliação do controle da cadeia produtiva de coca e o narcotráfico, assim como o objetivo de cercar militarmente a zona sul do país para evitar a expansão dos grupos guerrilheiros. Por outra parte, a violência em Samaniego está latente, mesmo depois da assinatura do acordo de paz. Isso deve-se, principalmente, ao controle que os grupos armados têm sob os recursos humanos e naturais na cadeia produtiva da coca, assim como os fenômenos de deslocamento forçado das comunidades 
afetadas pelas fumigações com glifosato em Putumayo ${ }^{5}$ (CNMH, 2016b; CNMH, 2017). Samaniego compartilha as condições de violência e narcotráfico com a região vizinha do Andén Pacífico, sendo que essa última constituiu-se nos anos recentes um porto importante onde produz-se, transforma e comercializa e distribui a pasta de coca e a cocaína ${ }^{6}$ (CNMH, 2016b; CNMH, 2017; OCHA, 2018).

Finalmente, em Florencia, a violência tem persistido por mais tempo e os custos sociais e econômicos têm sido mais altos. Historicamente, o conflito está associado com a disputa por recursos naturais e pela terra, assim como pelas contradições dos planos de desenvolvimento e ocupação da Região Amazónica, os quais priorizaram estratégias para a construção de estradas, crédito e titulação de terras visando atrair colonos que estavam fugindo durante o período de La Violencia ${ }^{7}$ desde os anos 1940. No entanto, os colonos ficaram à deriva e imersos num clima de confrontações. Isso gerou conflitos sociais de ocupação e uso do território devido à expansão da fronteira agrícola sem geração de investimento, à concentração da propriedade em atividades como criação de gado e exploração de petróleo e à homogeneização da aplicação de tecnologia (CORREA, 1994).

Em Caquetá, os grupos guerrilheiros foram surgindo em períodos diferentes. Primeiramente, as FARC-EP configuraram-se como um ator importante desde 1964. A partir de 1981, o Movimento 19 de Abril (M-19) conformou-se com o Frente Sur. Nesse mesmo período, o ELN e o Exército Popular de Libertação (EPL) operaram de forma muito fraca. Adicionalmente, a partir de 1998, o projeto paramilitar entrou no território com os irmãos Castaño Gil, com contribuições importantes na violência armada, mas sem chegar a ter uma forte influência sobre as bases sociais das comunidades e persistindo após a desmobilização de 2005 como as Águias Negras (Bandas Criminais- BACRIM) (CIRO, 2013).

O conflito armado nessa região relaciona-se com as estratégias militares contra os subversivos e com as intervenções para a erradicação de cultivos ilícitos, colocando o Exército Nacional como um ator chave do conflito, através de políticas como o Plan Colombia e a Política de Seguridad Democratica, assim como o Plan Nacional de Rehabilitación e o Plan Consolidación (CIRO, 2016).

Pelo exposto, nota-se a complexidade da violência armada nos municípios da Colômbia, que tem modificado as redes agroalimentares locais e os mecanismos de abastecimento. Vale frisar que os fluxos de abastecimento foram um elemento particularmente disputado durante o conflito armado. Mas as estratégias de organização comunitária também têm sido um elemento de controle dos grupos armados em conflito, que têm enfraquecido a coesão social por mecanismos violentos de estigmatização, intimidação e assassinatos. O Centro Nacional de Memoria Histórica (CNMH) tem desenvolvido estudos aprofundados dos fenômenos de violência no território nacional, muitos dos seus informes apresentam a comida e

\footnotetext{
5 As aspersões aéreas com glifosato têm sido adotadas e justificadas como política de erradicação dos cultivos ilícitos (principalmente coca, maconha e amapola), mas que depois de vários anos de implementação da política, não tem atingido os resultados esperados. Em contramão, essa política tem conduzido a efeitos perversos nas esferas sociais, ecológicas, militares e de soberania nacional (SÁNCHEZ, 2005).

${ }^{6}$ A importância da região do Andén Sur é a sua localização geográfica estratégica. Em primeiro lugar, ela fica na zona sul do país sobre o Litoral Pacífico, o que facilita o escoamento da produção de cocaína por via marítima. Em segundo lugar, a produção intensiva de coca é favorecida pelas dificuldades de acesso terrestre aos centros povoados, a limita rede para o escoamento de outros produtos agrícolas e alta disponibilidade de mão de obra camponesa.

7 La Violencia aconteceu após o assassinato de Jorge Eliecer Gaitán. Ela foi um dos motores da expulsão das comunidades rurais. O fenômeno durou duas décadas, cobrou mais de 200.000 mortes, 1 milhão de deslocamentos forçados e 200.000 sítios apropriados (ZAMOSC, 1986).
} 
a estigmatização das populações rurais como mecanismos de controle territorial. Isso obedece a formas de enfraquecer o tecido social das comunidades dentro do contexto da guerra armada, na lógica de "para pegar o peixe [inimigo] há que tirar a água" (CNMH, 2016a, p. 99-100, p. 229; CNMH, 2017, p. 98-102).

A pressão social durante o conflito armado modificou até mesmo as dinâmicas territoriais e a paisagem, incluindo os efeitos do deslocamento forçado. Os habitantes que retornaram aos seus territórios de origem tiveram de encaram o desafio de reconstruir o tecido social e comunitário e assegurar formas de reprodução nas zonas rurais. Ao questionar os camponeses sobre o que encontravam ao regressar às suas terras, a resposta constante era as casas caídas, sem janelas, sem teto, sem portas e com rastrojo (vegetação invadindo o espaço). Adicionalmente, as dinâmicas da agricultura e o abastecimento também foram afetadas pelo conflito armado, como as entrevistas evidenciam:

\begin{abstract}
quando as pessoas retornam encontram rastrojo. O sítio sozinho. Muitos temos voltado e a gente acolhe aos outros que chegam. Aqui era muito sozinho. Aqui a gente sente vontade de ficar, na cidade não. Meu marido sofria de depressão e aqui não, ele fica no sítio (Tradução própria, Interlocutora 1, 9 de abril 2018).

Faz anos a gente via sair esses carros [chamados de escaleras ou chivas] cheios de comida e pessoas, cima do teto do carro e pendurados aos lados... Agora os carros saem vazios. São poucas as pessoas que há. Os carros saíam das comunidades produtoras de café cheios de pessoas e de café, mas a dinâmica mudou muito. Há muitas pessoas que vem de outras partes e terras com outras culturas. A gente não voltará a ver a dinâmica que tivemos (Tradução própria, Intelocutor 2, 3 de abril de 2018).
\end{abstract}

Os resultados demonstram que não só as dinâmicas da agricultura e a alimentação mudaram nos territórios depois do conflito, mas também as relações sociais. Os custos econômicos e sociais do deslocamento forçado têm sido altos. Uma consequência da violência e outras dinâmicas recentes da agricultura tem sido a reconfiguração das redes agroalimentares nos territórios (FAJARDO, 2014).

Adicionalmente, as redes agroalimentares não só foram afetadas pelo controle territorial dos grupos armados e o deslocamento forçado, como também pela reestruturação da produção e a vocação agrícola, efeito do aumento do cultivo de coca nos municípios analisados.

Anteriormente, Caquetá exportava banana da terra, arroz e milho. Chegou a coca e acabou com a atividade agrícola do Estado... Era curioso, com a coca as pessoas do rural iam ao centro povoado para comprar banana da terra. Tinham hectares de coca e nem dizer que pelo menos uma planta de banana da terra para o autoconsumo. A coca acabou com os outros cultivos no Estado (Tradução própria, Interlocutor 3, 7 de fevereiro de 2018).

Até 2012 [e desde 1974], os cultivos de coca desmontaram as culturas alimentares. Emergiram redes de comercialização prioritariamente desde Florencia [e mais amplamente desde o Estado de Huila] e pelo rio Caguán. As pessoas começaram a comer de sacolão de loja. Todos comem, mas ninguém se alimenta. Perdeu-se o valor ancestral da produção da comida (Tradução própria, Interlocutor 4, 20 de fevereiro de 2018). 
Desse modo, as dinâmicas produtivas nas zonas rurais produtoras de coca modificaram-se deslocando outras atividades econômicas a causa de reconfigurações das relações de poder que se desenvolvem nessas zonas $(\mathrm{HOUGH}$, 2011). Adicionalmente, as políticas e estratégias de desenvolvimento que seguiram à apertura econômica nos anos 1990 também têm contribuído para o aumento das zonas cultivadas com coca (FAJARDO, 2014). A coca coloca-se como instrumento de reprodução e reconhecimento social camponês numa luta constante por encarar os mecanismos que a colocam no patamar da ilegalidade (CIRO, 2017).

A alimentação posiciona-se como um mecanismo importante para ativar a economia camponesa nos lugares afetados pelo conflito e permitir a reprodução social das comunidades. A violência na Colômbia tem sido um reflexo das inequidades econômicas e sociais nas zonas rurais, e é preciso formas de equilibrar essas desigualdades por meio de mecanismos que reduzam os efeitos desses conflitos (BERRY, 2017). Assim, assegurar formas para a reprodução de vida, incluindo estratégias de ativação da economia camponesa e o melhoramento dos serviços, infraestrutura e atenção primária, corresponde a formas efetivas para saldar a dívida com as comunidades rurais, especialmente as afetadas pelo conflito armado (PNUD, 2011). Esse debate não deve ficar atrelado só as discussões do acesso a direitos, mas também às formas de acesso, manutenção e controle equitativo de recursos e reconhecimento pelos diferentes grupos de atores (RIBOT e PELUSO, 2003).

Assim, a reconstrução das redes agroalimentares dentro das zonas afetadas pelo conflito armado pode ser um dos mecanismos que suportariam a reconstrução dos laços sociais dentro da vida pública e comunitária das comunidades afetadas. As redes agroalimentares que suportem essas dinâmicas são as que fomentam as relações de proximidade entre produtores e consumidores dentro de lógicas que ultrapassam a concepção reduzida do interesse no lucro econômico.

Durante o trabalho de campo indagou-se sobre as transformações no abastecimento dos programas de alimentação pública. Os interlocutores expressaram múltiplas contradições em relação ao melhoramento ou limitações das compras públicas locais. Resultado das mudanças institucionais nos últimos anos. Um grupo de atores expressa as vantagens das normatividades para a gestão dos programas, enquanto outros explicam os fenômenos de exclusão gerados a partir dessas decisões:

\begin{abstract}
basicamente, o programa nos últimos anos, quando passou do ICBF ao Ministério de Educação Nacional (MEN), tem criado diretrizes para melhorar a prestação do serviço. Como eu falo para todos, as normas e as regulamentações funcionam quando estão muito bem estruturadas e amparam muitas atividades do processo .... O município contrata um provedor com capacidade financeira importante e que tenha a capacidade, experiência e idoneidade para a entrega dos alimentos sob um patamar de qualidade e quantidade estabelecidos (Tradução própria, Interlocutor 5, 22 de março de 2018).

Faz 6 anos que a avaliação não foi positiva para seguir operando com as associações de pais ${ }^{8}$. São operados por entidades que têm
\end{abstract}

\footnotetext{
${ }^{8}$ As associações de pais são figuras jurídicas legais criadas dentro da institucionalidade do ICBF, as quais desempenham funções importantes para a prestação dos serviços nos programas de atenção do ICBF. Elas têm sido excluídas dos processos de licitação por não ter a capacidade de cumprir com os quadros normativos impostos através das diretrizes do Banco Nacional de Oferentes do ICBF.
} 
passado por um filtro que chama-se de Banco Nacional de Oferentes (do ICBF) e que têm capacidade financeira, administrativa e técnica, para responder às exigências. Isso é só prós, porque têm que ser empresas com muitas competências para poder operar (Tradução própria, Interlocutor 6, 14 de fevereiro de 2018).

Já não existem as associações, na medida que foram fazendo leis, as associações acabaram-se, já isso não existe. Só existem os que se apropriam do dinheiro, os operadores. Eles licitam e o melhor ofertante é quem fica [com o contrato] (Tradução própria, Interlocutor 7, 8 de fevereiro de 2018).

Os depoimentos acima evidenciam que existem concepções contraditórias em relação aos grupo de atores e os tipos de agência mais adequadas para a gestão dos programas de alimentação. Essas discussões vêm acontecendo espaços públicos e tem influenciado mudanças normativas para a aquisição de alimentos. Esses quadros normativos têm dado condições favoráveis de contratação para os grupos de atores mais capacitados, enquanto excluem as possibilidades de venda direta dos produtos camponeses dentro dos programas.

Destrinchar as complexas relações sociais que ocorrem nos modos de operacionalização do prato público permite evidenciar que os quadros normativos estão priorizando significados conflitivos que parecem não apenas limitar a participação das comunidades, mas também afetam as condições e possibilidades de assegurar uma alimentação de qualidade.

\section{Campos de ação estratégica e possibilismo}

Acreditamos que os elementos da teoria dos campos de ação estratégica, elaborada por Fligstein e McAdam (2011) e a abordagem possibilista de Hirschman (1957, 1968b, 1970), podem fornecer o arcabouço conceitual apropriado para analisar o caso das compras públicas e das estratégias de alimentação que estão sendo desenvolvidas na Colômbia.

A teoria dos campos de ação estratégica é uma abordagem institucionalista que dialoga com as teorias dos movimentos sociais, da sociologia política e econômica e das organizações. Por meio dessa teoria podemos analisar a alimentação pública como campo em disputa, no qual os diferentes atores mobilizam recursos, criam estratégias de ação coletiva e lutam por reconhecimento dentro do campo. Por outra parte, a abordagem possibilista de Hirschman construí a suas bases teóricas analisando as dinâmicas dos países de desenvolvimento tardio, assim como estratégias de intervenção aplicadas em tempos de crise. Por meio da abordagem possibilista podemos identificar os mecanismos de ação que intervém na mobilidade da alimentação entre as esferas público e privada. Adicionalmente, podemos resgatar da invisibilidade as estratégias de organização que são negligenciadas pelos quadros normativos e as concepções homogeneizadoras na gestão dos programas públicos de alimentação.

Dentro do campo, os atores disputam constantemente sua reprodução e posição social, através da construção de significados e arranjos (FLIGSTEIN e MCADAM, 2011, p. 17; KLUTTZ e FLIGSTEIN, 2016). Assim, os atores mobilizam recursos, fazem alianças e (re)constroem quadros normativos e significados 
(FLIGSTEIN, 2005). Para Fligstein, os quadros normativos são os acordos construídos entre os atores que definem as relações de competição e cooperação e a forma como os atores podem beneficiar-se e negociar dentro do campo (FLIGSTEIN, 2002, p. 71). Eles determinam a posição dos atores frente aos outros e permitem a sua reprodução e sobrevivência (FLIGSTEIN e MCADAM, 2012, p. 11). Dessa forma, os quadros normativos restringem as possibilidades de aquisição de alimentos produzidos localmente, tanto no que se refere à contratação pública, quanto às concepções de qualidade dos alimentos. No entanto, os atores, frequentemente, disputam significados e criam estratégias de contenção dentro desses campos em disputa. Dessa forma, eles têm a capacidade de compreender as dinâmicas sociais do campo e induzir linhas de ação para estabelecer a cooperação e a ação coletiva dos outros atores (FLIGSTEIN, 1997; FLIGSTEIN e MCADAM, 2011, p. 4; KLUTTZ e FLIGSTEIN, 2016).

Segundo Hirschman (1996), a alimentação integra-se à esfera privada, uma vez que não há nada mais individual do que o ato de alimentar o próprio corpo. No entanto, a alimentação é tão indispensável para a vida que se coloca como um elemento próprio da esfera coletiva. Por essa razão é que a alimentação é tão poderosa, ela entrelaça as pessoas pela sua capacidade de construir relações sociais e reproduzir a vida. Para a nossa análise, é importante identificar como o prato público ${ }^{9}$ transita constantemente nas esferas público-privada, e vice-versa. Segundo Hirschman (1986a), o trânsito da esfera pública à privada ocorre pela frustração ou pela sua apropriação derivada a um interesse individual. Em sentido contrário, o trânsito para arena pública é consequência da mobilização e das ações coletivas pelo interesse na consecução de um objetivo (HIRSCHMAN, 1980, p. 72, 101).

Para abordar a questão da alimentação no âmbito dos campo em disputa, é preciso considerar que os diferentes atores mobilizam significados, discursos, regras e recursos para assegurar a sua reprodução social neste espaço. Por um lado, a alimentação pública pode ser um mecanismo de desenvolvimento econômico e social das pessoas e das comunidades, assim como fazer parte da engrenagem necessária para quebrar os ciclos de miséria e fome em grupos sociais vulneráveis (DORWARD et al., 2006; MCCRUDDEN, 2004; SABATES-WHEELER et al., 2009). Por outro lado, o prato público tem sido apropriado pelas retóricas do aumento da eficiência para a redução do gasto público, o que têm conduzido à priorização do preço em contramão da perda da diversidade alimentar e uma redução da qualidade dos cardápios (MORGAN e MORLEY, 2014). Adicionalmente, o prato público também tem sido fortemente moldado pelo neoliberalismo (MCCRUDDEN, 1999).

Dessa forma, os programas de alimentação têm transitado da esfera pública à privada. Assim, o prato público tem sido apropriado pelo setor privado em complexas redes que se apoiam em discursos de racionalização do gasto público, descentralização sem desconcentração e cumprimento de padrões internacionais de qualidade. No entanto, contínua e frequentemente as formas organizativas da gestão comunitária e autônoma realocam os programas de alimentação novamente na esfera pública. Essas formas de gestão conduzem a processos de coesão social,

9 O prato público são as formas de governabilidade recriadas por meio da aquisição de alimentos nos programas públicos de alimentação, as quais perpassam lógicas reduzidas à geração do lucro econômico e posicionam a alimentação como mecanismo multifuncional e multidimensional. Nesse campo, o Estado tem uma função importante para contrabalançar o jogo de força dentro das relações do poder dos mercados institucionais (MORGAN, 2014). 
mediante a canalização da sua força coletiva, tecendo relações diretas entre atores de uma mesma comunidade em busca de alcançar um fim coletivo.

\title{
4 Os quadros normativos em disputa: valores e significados mobilizados na alimentação pública
}

O caso colombiano mostra que o prato público constantemente tenta ser apropriado na esfera privada por quadros normativos influenciam as relações entre os atores e minimizam a capacidade de agência das comunidades rurais.

No entanto, alguns elementos são desafiados constantemente pelos diferentes atores sociais. Em primeiro lugar, o significado de qualidade dos alimentos é um elemento importante. Os seguintes depoimentos evidenciam os conflitos existentes em relação à qualidade dos alimentos:

\begin{abstract}
se tenho parâmetros técnicos que me verifiquem: tipo de alimento, estado de amadurecimento, tamanho do alimento que vai ser entregue, estou garantindo que os produtos sejam de ótima qualidade (Tradução própria, Interlocutor 4, 22 de março de 2018).

A qualidade dos produtos que chegavam era extremamente mal, porque chegavam os produtos de fora. Então, tudo chegava de terceira [do mais inferior], chegavam muitas vezes estragados, apodrecidos (Tradução própria, Interlocutor 8, 9 de maio de 2018).

Para a rapadura e os ovos colocaram problemas porque os [que se produzem] daqui não serviam porque não tinham rótulo nem data de validade. Então, as associações de rapadura tiveram que começar fazer os rótulos. Diziam que os ovos daqui estavam contaminados, quando os que chegavam de fora tinham que ser quebrados um a um porque chegavam apodrecidos e quebrados" (Tradução própria, Interlocutor 9, 5 de abril de 2018).
\end{abstract}

No campo da alimentação pública é evidente a hegemonia que os significados de inocuidade e as normatividades sanitárias ocupam no abastecimento dos programas públicos. Os conflitos em relação à qualidade dos alimentos emergem dentro do campo e os significados são regulados e validados conforme o quadro normativo existente, o que desconhece não só os contextos e preferências alimentares das comunidades, como também as possibilidades de inserir os produtos locais dentro do mercado institucional.

Outro elemento que nos últimos anos tem sido disputado é a quantidade de alimento a ser servido. Um diálogo com a maioria dos interlocutores chama a atenção sobre a insatisfação da quantidade da porção recebida. A quantidade servida nas zonas rurais corresponde a um padrão nacional segundo a faixa etária. No entanto, esse padrão desconhece as condições das longas distâncias e esforço físico das crianças, assim como a demanda energética e os costumes alimentares das populações rurais. A limitação da quantidade perpetua-se na mesma racionalidade econômica do setor público, que pressionado por um orçamento limitado tem reduzido, nos últimos anos, a quantidade dos alimentos servidos. Essa mesma racionalização inter-relaciona-se com processos de descentralização sem desconcentração e apropriação do setor público por empresas ou operadoras privadas, ao mesmo tempo que se molda com o modelo de desenvolvimento 
neoliberal que restringe a capacidade de intervenção do setor público que subordinase ao capital privado.

Finalmente, a eficiência e qualidade do serviço prestado também é um elemento que se disputa dentro do campo, especialmente no que tange a normatividade da contratação pública. Comparando as modalidades atuais de aquisição com os anos anteriores, tem se observado um fenômeno de padronização. Assim, as formas heterogêneas da aquisição para o abastecimento dos programas têm sido substituídas pela contratação de operadores ou empresas privadas, excluindo ou moldando as relações entre os múltiplos atores que interagem. Conforme os atores ficam distanciados e as atividades ficam concentradas num pequeno grupo, reduz-se a capacidade de interação e aumentam-se as assimetrias de poder dentro do campo.

A eficiência do serviço, na forma como funcionam os programas atualmente, desconsidera um elemento importante da discussão: as redes de abastecimento. Os alimentos tendem a ser transportados por longas distâncias até os centros de abastecimento e de volta aos municípios dentro dessas redes agroalimentares desconexas. Essa desconexão entre agricultores e programas públicos em alimentação relaciona-se com a intermediação que dificulta a aquisição direta de alimentos no prato público (GELLI et al., 2016). Na Colômbia, como explicado na seção anterior, um dos resultados da guerra foi a desconexão do abastecimento alimentar e a dependência de mercados fora desses espaços. Assim, a reconexão dessas redes de abastecimento alimentar por meio do prato público deveria ser prioridade na agenda política e social.

Os dados evidenciam que acontece um trânsito da alimentação pública à esfera privada (HIRSCHMAN, 1980; HIRSCHMAN, 1986a). Em primeiro lugar, algumas mudanças institucionais e normativas têm reduzido o papel do Estado e o seu poder de decisão sobre o prato público. Adicionalmente, as tentativas de modernizar a alimentação pública a partir das ópticas da padronização da eficiência da gestão pública e dos altos parâmetros de qualidade estão limitando as possibilidades que o prato público tem para ser um mecanismo de desenvolvimento das comunidades rurais.

Em segundo lugar, o vazio estatal tem sido preenchido pelos atores mais capacitados dentro dessas concepções, arranjos e normativas de controle impostas desde e pela esfera pública. No entanto, evidencia-se que o trânsito da alimentação pública para a esfera privada também acontece pelas alianças entre atores do poder público, tanto do executivo quanto dos entes de controle, e a esfera privada, colocando em evidência os múltiplos interesses individuais em jogo.

O prato público tem transitado à esfera privada desde onde os espaços de agência social são apropriados e os significados são moldados e reconfigurados, sendo que os operadores privados têm ocupado um lugar privilegiado dentro do campo estratégico. Esses últimos têm tentado reduzir a alimentação à mercadoria geradora de lucro, o que se materializa na aquisição de alimentos de menor preço, de baixa qualidade e em redes agroalimentares desconexas.

Porém, nos últimos anos os programas de alimentação estão sendo apropriados por grupos de atores que detêm e controlam mais recursos materiais e imateriais, enquanto as comunidades continuam posicionando a alimentação como estratégia de desenvolvimento. O prato público mobiliza, nas comunidades 
estudadas, múltiplas ações coletivas que garantem a satisfação das necessidades alimentares básicas. Essa discussão será abordada na próxima seção.

\section{Discussão: mobilização de recursos e estratégias comunitárias e autônomas}

Nesta seção, a partir dos relatos dos atores, pretendemos resgatar as formas como a gestão comunitária e autônoma vincula uma rede de estratégias que mobilizam recursos dentro do campo para a consecução de fins relacionados não só com a segurança alimentar e nutricional, mas também com iniciativas de coesão social. Assim, essa seção explora como a comunidade conserva e transmuta a energia, canalizando a sua força coletiva (HIRSCHMAN, 1986b).

Como explicado na seção anterior, o Estado tem desconhecido e negligenciado as capacidades existentes nas comunidades rurais, priorizando significados conflitivos em relação às regulações de contratação e à aquisição de alimentos. Consequentemente, o desconhecimento dos recursos existentes dentro das comunidades, em termos de capacidades humanas e recursos materiais, assim como o desconhecimento das trajetórias históricas de fracassos e sucessos do prato público estão limitando as possibilidades de percorrer os múltiplos caminhos do desenvolvimento, que podem ser conduzidos por meio da alimentação pública (HIRSCHMAN, 1968a; HIRCHMAN, 1970). Relatar esses depoimentos a partir da voz das comunidades rurais é uma forma de visibilizar as suas estratégias de organização comunitária e trazer elementos para repensar as estratégias de política pública. $\mathrm{Na}$ sequência, apresentam-se as dinâmicas que emergiam a partir dessas formas de organização comunitária e autônoma:

antes a maioria das coisas comprava-se aqui no mercado ou na loja local. Antes tinha uma associação de pais. A associação de pais era quem direcionava o recurso. A alimentação era excelente antes e comprava-se no mesmo município. A associação funcionou até 2011 (Tradução própria, Interloculor 10, 28 de março de 2018).

Propusemos que o serviço fosse operado pela Asocomunal (entidade sem fins lucrativos, de segundo nível ${ }^{10}$, que reúne todas as Juntas de Acción Comunal $\left.{ }^{11}\right)[. .$.$] Sempre ao final do ano escolar tinham dinheiro e as crianças$ nunca ficaram sem restaurante. Como os recursos eram comunitários, a Junta de Acción Comunal definia o destino dos saldos, quase sempre se destinava à comemoração do natal comunitário com natilla, buñuelos... e fazia-se entrega de um presente a cada criança, como calças esportivas ou botas, para reconhecer o trabalho em comunidade (Tradução própria, Interlocutor 11, 12 de abril de 2018).

Neste sentido, nossa pesquisa permitiu evidenciar que algumas comunidades são capazes de criar soluções criativas em tempos de crise. Durante o trabalho de campo, quando (os interlocutores) perguntados se o alimento recebido seria o suficiente para alimentar todas as crianças, sempre se ouviu um constante, uníssono e enérgico: NÃO.

\footnotetext{
${ }^{10}$ O segundo nível faz referência ao nível organizacional. Ou seja, as organizações do segundo nível são mais complexas, pois agrupam várias organizações do primeiro nível.

${ }^{11}$ As Juntas de Acción Comunal é a forma de organização política e coletiva mais descentralizada do país. Normalmente, são conformadas ao nível das comunidades locais, chamadas na Colômbia de veredas.
} 
Compreender como as comunidades desafiam os quadros normativos da alimentação pública, buscando encontrar formas próprias para suprir os déficits dos programas da alimentação pública de forma heterogênea, evidencia que as comunidades procuram múltiplos caminhos para garantir a sua reprodução social. Segundo Hirschman (1957), a tentativa de tornar eficientes alguns setores produtivos, por meio do investimento intensivo em capital, podem estar levando ao fracasso essas estratégias. O presente estudo evidência que estratégias criativas emergem das mesmas comunidades e desafiam as concepções contraditórias da modernização na gestão dos programas de alimentação. Isso sugere que as prioridades que devem ser alavancadas no caminho ao desenvolvimento das sociedades de desenvolvimento tardio, as quais possuem abundante capacidade de trabalho e limitado capital de investimento. A análise possibilista de Hirschman desafia a visibilizar as estratégias ocultas que podem estar conduzindo à perda constante das oportunidades para o desenvolvimento (HIRSCHMAN, 1968a). A pesquisa coloca em evidência as contradições dos modelos de gestão da alimentação, em que as formas de organização comunitárias e autônomas, continuamente, são ocultas e negligenciadas, ainda que sejam muito importantes para as discussões contemporâneas sobre alimentação, agricultura e desenvolvimento.

Atualmente, os impasses gerados por uma alimentação pública de baixa qualidade, por entregas incompletas e recursos insuficientes, animam formas de organização comunitárias que se contrapõem a visão assistencialista dos programas públicos. Alguns depoimentos exemplificam essas situações:

\begin{abstract}
como as entregas são muito escassas, os pais mandam frutas [guaiava e limão] e vários alimentos [banana da terra e arroz] para que as crianças não comam tão pouco. No campo, as pessoas comem com o seu morrinho no prato [ou seja, abundante]. Às vezes, as crianças saíam da escola com fome, então eles [os pais] mandam de casa para aumentar a quantidade (Tradução própria, Interlocutor 12, 2 de abril de 2018).

Antes a batata e as verduras eram produzidas na horta escolar e se compravam aqui na escola por menor preço. Ainda a horta escolar compartilha com o restaurante: morangos, lulos ${ }^{12}$, tomates de fruta, tomates de árvore, alface, acelga. Isso [agora] é a contribuição da mesma escola em tempo de safra (Tradução própria, Interlocutor 13, 26 de fevereiro de 2018).

Há coisas que não são tão limitantes. Por exemplo, pode-se trocar um pacote de pão em fatias, que vem de fora por meio quilo de lentilhas ou por mais arroz ou azeite. Algo com o que fazer uma sopa, ou uma sardinha ou um atum. Pode-se fazer algo diferente e me parece que não está errado de fazer, é algo de valorar (Tradução própria, Interlocutor 14, 7 de abril de 2018).
\end{abstract}

A gestão comunitária e autônoma leva a formas de recriar espaços e processos sociais que demostram a capacidade dos atores de responder a impasses dentro dos campos. Segundo Fligstein e Mcadam (2012), a habilidade social de atores estratégicos desafiadores dá lugar à criação, interpretação e suporte de significados,

${ }^{12}$ O lulo é o fruto da planta perene subtropical do noroeste da América do Sul, seu nome científico é Solanum quitoense. 
identidades, interesses e mundos compartilhados, para através da agência desenvolver ações por objetivos comuns (FLIGSTEIN e MCADAM, 2012, p. 46-50).

Mesmo em condições econômicas de pobreza, as comunidades organizam-se de múltiplas formas. Existem aportes em dinheiro ou produtos provenientes das mesmas famílias camponesas ou da comunidade para complementar a alimentação recebida, para comprar gás ou utensílios de limpeza, que não são supridos, ou para reconhecer, em dinheiro, parte do trabalho das merendeiras, o qual muitas vezes é voluntário. Além disso, organizam-se atividades culturais e sociais para coletar fundos econômicos destinados à alimentação das crianças. Também são realizadas permutas nas mercearias locais, de produtos de maior valor e baixa aceitação pelas crianças por outros produtos mais requisitados no restaurante escolar. Finalmente, algumas escolas mantêm uma horta com a qual complementam parte da alimentação.

Os efeitos dessas formas de organização são múltiplos. Em primeiro lugar, aproveitam-se as capacidades humanas e econômicas do território, tornando os processos mais eficientes e econômicos. Em segundo lugar, encurtam-se os fluxos alimentares durante o abastecimento, melhorando a qualidade do alimento fornecido e propiciando a interconexão de relações nos espaços rurais com conflito armado. Ainda, fomenta-se a autonomia de decidir qual alimento colocar no prato das crianças. E, finalmente, essa autonomia permite construir projetos comuns que fortalecem os laços sociais entre as comunidades, construindo coletivamente estratégias que empreguem as capacidades dos seus próprios membros, os recursos disponíveis e priorizam as atividades a serem desenvolvidas (HIRSCHMAN e LINDBLOM, 1960; HIRSCHMAN, 1968b).

Essas estratégias são ações que perpassam e desafiam os quadros normativos estabelecidos, ao mesmo tempo que sinalizam caminhos diferentes de desenvolvimento, como Hirschman comentava, a "arte de promover o desenvolvimento" não vem com estratégias únicas nem soluções integrais, ela emerge de espaços sociais múltiplos, ainda submetidos à invisibilidade (MALUF, 2015). Adicionalmente, a gestão comunitária e autônoma permite o trânsito do prato público da esfera privada novamente à esfera pública, devido à mobilização de interesses coletivos, principalmente na busca do bem-estar das comunidades. No entanto, em algumas comunidades não conseguem desenvolver essas estratégias e os programas de alimentação limitam-se ou ficam presos na esfera privada. Como resultado da falta de alimentação, as crianças desistem de frequentar as instituições educativas, ou os pais terminam tomando decisões que desconsideram o coletivo, como levar ou dar para levar a comida das suas próprias casas.

\section{Considerações finais}

A alimentação pública é um mecanismo de desenvolvimento. Em primeiro lugar, ela é um instrumento de justiça social ao suprir as necessidades alimentares de populações vulneráveis e ao quebrar os ciclos de pobreza dessas comunidades ao longo prazo. Em segundo lugar, a alimentação pública pode ser um instrumento para o fortalecimento do tecido produtivo e social quando permite a aquisição de alimentos produzidos nas mesmas comunidades. Ela é um mecanismo de duplo efeito: de um lado permite a inclusão produtiva das comunidades assegurando a redistribuição de renda, e do outro lado aumenta a eficiência na logística e 
distribuição de alimentos, o que permite brindar uma alimentação mais fresca, acorde aos hábitos alimentares das comunidades e com maior autonomia nas escolhas de consumo.

O conflito armado na Colômbia tem modificado as redes agroalimentares nas zonas rurais. A alimentação tem sido um elemento de disputa dentro do conflito pelos diferentes grupos armados com o objetivo de controlar os fluxos humanos e submeter às comunidades rurais como estratégia de guerra. A procura e implementação de mecanismos que permitam a permanência dessas comunidades, assim como estratégias que permitam contrabalancear o jogo de forças nos territórios de conflito constituem formas de construir uma paz estável e duradoura. O prato público se perfila como um mecanismo importante para a consecução desse fim.

O estudo apresenta as transformações dos programas de alimentação pública visibilizando os conflitos que têm emergido pelas disputas de significados dentro desse campo. Apresentam-se, a partir da perspectiva dos Campos de Ação Estratégica e da Abordagem Possibilista de Albert Hirschman, as formas como os atores (re)criam e agenciam recursos para conseguir a sua reprodução social e o desenvolvimento das suas comunidades.

O prato público transita entre as esferas pública e privada. Em primeiro lugar, a alimentação pública continuamente é apropriada na esfera privada pelos quadros normativos e pelas lógicas que visam o lucro econômico. No entanto, em tempos recentes de crise, algumas comunidades se organizam para assegurar sua reprodução social suprindo as deficiências do prato público que foi apropriado pelos operadores privados. O estudo permite visibilizar as estratégias coletivas que se contrapõem a esses quadros normativos. Ao final, quem está enchendo o prato público vazio na Colômbia é a ação coletiva das comunidades.

As transformações da alimentação pública nos anos recentes, evidenciam como o Estado tem priorizado lógicas tecnicistas com excludentes quadros normativos. Esses quadros normativos têm definido os parâmetros de qualidade e quantidade de alimentos, assim como as formas de contratação e a operação do prato público. Dentro das comunidades continuamente emergem conflitos por esses quadros normativos, sendo que eles têm permitido aos grupos de atores mais capacitados da esfera privada apropriar-se do prato público. O efeito sobre o prato público tem sido a conformação de redes agroalimentares longas e a redução do prato público às lógicas da busca pelo seu próprio lucro. Isso tem conduzido ao enfraquecimento das relações sociais e a cardápios insuficientes e desconectados dos hábitos alimentares das populações rurais.

Não obstante, ainda que o prato público esteja sendo apropriado pelo setor privado, algumas comunidades têm mobilizado significados compartilhados por interesses e motivações comuns para empregar recursos e habilidades disponíveis e encarar os desafios da alimentação pública. Assim, estratégias organizativas das comunidades levam o prato público alimentação de novo à esfera pública. O caso colombiano evidência que a alimentação se posiciona como mecanismo para impulsionar processos organizativos que contribuem de forma positiva à construção de tecido social e produtivo. 


\section{REFERÊNCIAS}

ARUMUGAM, A. Social protection for food security - a study of mid-day meal scheme in India. International Journal of Business and Administration Research Review, v. 2, n. 9, p. 58-67, 2015.

BARBOSA-GONÇALVES, $\mathrm{H}$ et al. Produtos da agricultura familiar nos cardápios da alimentação escolar: uma parceria para promoção da alimentação saudável. Cienc. Rural, v.45, n.12, p. 2268 - 2273, 2015.

BERRY, A. Reflections on injustice, inequality and land conflict in Colombia. Canadian Journal of Latin American and Caribbean Studies, v. 42, n. 3, p. 277 - 297, 2017.

BERNAL, R. Diagnóstico y recomendaciones para la atención de calidad a la primera infancia en Colombia. Cuadernos Fedesarrollo, v. 51, p. 13 - 77, 2014.

BLESH, J.; WITTMAN, H. Food Sovereignty and Fome Zero: Connecting Public Food Procurement Programmes to Sustainable Rural Development in Brazil. Journal of Agrarian Change, v. 17, n. 1, 81-105, 2015.

BUCKLEY, J. et al. Social relationships and farm-to-institution initiatives: complexity and scale in local food systems. Journal of Hunger \& Environmental Nutrition, v. 8, n. 4, p. $397-412,2013$.

CNMH. Granada: memorias de guerra, resistencia y reconstrucción. Em: CNMH Colciencias - Corporación Región. [2016a]. Disponível em:

http://www.centrodememoriahistorica.gov.co/en/informes-2016/granada-memoriasde-guerra-resistencia-y-reconstruccion. Acesso em: 14 dec. 2018.

CNMH. Grupos Armados Posdesmovilización (2006 - 2015). Trayectorias, rupturas y continuidades. Em: CNMH [2016b]. Disponível em:

http://www.observatoriodetierras.org/wp-content/uploads/2017/05/gruposarmados-posdesmovilizacion-2006-2015-CNMH.pdf. Acesso em: 14 dec. 2018.

CNMH. La guerra escondida. Minas Antipersonal y Remanentes Explosivos en Colombia. Em: CNMH. [2017]. Disponível em:

http://www.centrodememoriahistorica.gov.co/de/informes-2017/informe-la-guerraescondida-minas-antipersonal-y-remanentes-explosivos-en-colombia. Acesso em: 14 dec. 2018.

CNMH; OMC. Geográficas. Em: CNMH. [2018]. Disponível em: http://centrodememoriahistorica.gov.co/observatorio/bases-de-datos/geograficas/. Acesso em: 14 dec. 2018.

CIRO, C.A. "Unos grises muy berracos" poder político local y configuración del estado en el Caquetá, 1980-2006. 2013. 152 f. Dissertação (Mestrado em Estudos 
Políticos) - Faculdade de Ciências Econômicas, Instituto de Estudos Políticos e Relações Internacionais, Universidad Nacional de Colombia, Bogotá, 2013.

CIRO, E. Cultivando coca en el Caquetá: vidas y legitimidades en la actividad cocalera. 2016. 258 f. Tese (Doutorado em Ciências Políticas e Socias)- Facultad de Ciencias Políticas y Sociales, Universidad Nacional Autónoma de México, Ciudad de México, 2016.

CONSTANTY, H.F.P.; ZONIN, W.J. Programa Nacional de Alimentação Escolar (PNAE) e sustentabilidade: o caso do município de Marechal Cândido Rondon. Desenvolv. Meio Ambiente, v. 36, p. 371-392, 2016.

CORREA, F. El sistema de información geográfica, políticas de reordenamiento del espacio amazónico colombiano: colonización, medio ambiente y protección de territorios indígenas, 1960-1990. Em: Seminario de perspectivas del desarrollo Amazónico. Florencia: Universidad de la Amazónia, 1994.

DANE. Tercer Censo Nacional Agropecuário. Em: DANE. [2016]. Disponível em: http://www.dane.gov.co/files/images/foros/foro-de-entrega-de-resultados-y-cierre-3censo-nacional-agropecuario/CNATomo2-Resultados.pdf. Acesso em: 10 out. 2016.

DANE. Censo General de 2005. Em: DANE. [2005]. Disponível em: https://www.dane.gov.co/index.php/estadisticas-por-tema/demografia-ypoblacion/censo-general-2005-1 Acesso em: 10 dec. 2018.

DEVEREUX, S. et al. Linking social protection and support to small farmer development. Em: FAO. [2008]. Disponível em: http://www.fao.org/fileadmin/templates/esa/Workshop_reports/Social_protection_ 2008/workshop_0108_social_protection.pdf Acesso em: 4 jun. 2016.

DNP. El campo colombiano: un camino hacia el bienestar y la paz. Em: DNP. [2015]. Disponível em:

https://colaboracion.dnp.gov.co/CDT/Agriculturapecuarioforestal\%20y\%2opesca/TO MO\%201.pdf Acesso em: 5 jan. 2016.

DORWARD, A.R. et al. Promoting Agriculture for Social Protection or Social Protection for Agriculture: Policy and Research Issues. Brighton: Future Agricultures Consortium, Institute of Development Studies, 2006.

FAJARDO, D. Las guerras de la agricultura colombiana, 1980-2010. Bogotá: Instituto Latinoamericano para una Sociedad y un Derecho Alternativos, 2014.

FAO. Alimentación escolar y las posibilidades de compra directa de la agricultura familiar. Estudio nacional de Colombia. Em: FAO. [2013] Disponível em: http://www.fao.org/docrep/field/oog/as513s/as513s.pdf. Acesso em: 15 ago. 2014. 
FLIGSTEIN, N. Social Skill and Institutional Theory. American Behavioral Scientist, v. 40, p. 397- 405, 1997.

FLIGSTEIN, N. The architecture of markets. An Economic sociology of twenty-firstcentury capitalist societies. New Jersey: Princeton University Press, 2002.

FLIGSTEIN, N. The Political and Economic Sociology of International Economic Arrangements. Em: SMELSER, N.; SWEDBERG, R. The Handbook of Economic Sociology. New York: Princeton University Press, 2005.

FLIGSTEIN, N.; MCADAM, D. Toward a general Theory of Strategic Action Fields. Sociological Theory, v. 29, n. 1, 2011.

FLIGSTEIN, N.; MCADAM, D. A Political-Cultural Approach to the Problem of Strategic Action. Em: COURPASSON, D. et al. Volume 34: Rethinking Power in Organizations, Institutions, and Markets. Research in the Sociology of Organizations, Emerald Group Publishing Limit, 2012.

FOEKEN, D, et al. School farming for school feeding: experiences from Nakuru, Kenya. Field Actions Science Reports, v. 1, 2010.

GELLI, A.; SUWA, Y. Investing in innovation: Trade-offs in the costs and costefficiency of school feeding using community based kitchens in Bangladesh. Food and Nutrition Bulletin, v. 35, n. 3, p. 327 - 337, 2014.

GELLI, A et al. Evaluation of alternative school feeding models on nutrition, education, agriculture and other social outcomes in Ghana: rationale, randomised design and baseline data. Trials, v. 17, p. 37 - 55, 2016.

HIRSCHMAN, A. Investment Policies and "Dualism" in Underdeveloped Countries. The American Economic Review, v. 47, n. 5, p. 550 - 570, 1957.

HIRSCHMAN, A.; LINDBLOM, C. Economic development, research and development, policy making: some converging views. ANATOL RAPOPOR, Fights, Games, and Debates, 1960.

HIRSCHMAN, A. Political Economy of Import-Substituting Industrialization in Latin America. The Quarterly Journal of Economics, v. 82, n. 1, p. 1 - 32, 1968a.

HIRSCHMAN, A. Underdevelopment, obstacles to the perception of change, and leadership. Daedalus, v. 97, n. 3, p. 925 - 937, 1968b.

HIRSCHMAN, A. The search for paradigms as a hindrance to understanding. World Politics, v. 22, n. 3, p. 329-343, 1970. 
HIRSCHMAN, A. Exit, voice, and loyalty. The Milbank Memorial Fund Quarterly. Health and Society, v. 58, n. 3, p. $430-453,1980$.

HIRSCHMAN, A. Interés privado y acción pública. México D.F.: Fondo de Cultura Económica S. A., 1986 a.

HIRSCHMAN, A. El avance en colectividad. Experimentos populares en la América Latina. Fondo de Cultura Económica: Serie de Economía, 1986b.

HIRSCHMAN, A. Melding the public and private spheres: Taking commmensality seriously. Critical Review: A Journal of Politics and Society, v. 10, n. 4, 1996.

HOUGH, P. Disarticulations and commodity chains: cattle, coca, and capital accumulation along Colombia's agricultural frontier. Environment and Planning A, v. 43, p. 1016-1034, 2011.

INTERNATIONAL FOOD POLICY RESEARCH INSTITUTE. Biodiversity for Food and Nutrition in Brazil. Em: IFPRI. A4NH Outcome Note. [2015]. Disponível em: http://ebrary.ifpri.org/utils/getfile/collection/p15738coll2/id/130120/filename/130331.p df. Acesso em: 13 dec. 2018.

KLUTTZ, D.; FLIGSTEIN, N. Varieties of Field Theory. Em: ABRUTYN, Seth. Handbook of Contemporary Sociological Theory. Memphis: Springer International Publishing, 2016.

MCCRUDDEN, C. International economic law and the pursuit of human rights: A framework for discussion of the legality of 'Selective Purchasing' Laws under the WTO Government Procurement Agreement. Journal of International Economic Law, v. 2, n. 1, p. 3-48, 1999.

MCCRUDDEN, C. Using public procurement to achieve social outcomes. Natural Resources Forum, v. 28, p. $257-267,2004$.

MALUF, R. Hirschman e a dessacralização da epopeia do desenvolvimento por um desenvolvimentista. Rev. Econ. Polit, v. 35, n. 1, 2015.

MASSET, E.; GELLI, A. Improving community development by linking agriculture, nutrition and education: design of a randomised trial of "home-grown" school feeding in Mali. Trials, v. 14, p. 55 - 78, 2013.

MIKKELSEN, B.E. et al. Are green caterers more likely to serve healthy meals than non-green caterers? Results from a quantitative study in Danish worksite catering. Public Health Nutrition, v. 9, n. 7, p. 846-850, 2006. 
MORGAN, K. The Politics of the Public Plate: School Food and Sustainability. Int. Jrnl. of Soc. of Agr. \& Food, v. 21, n. 3, p. 253-260, 2014.

MORGAN, K.; MORLEY, A. Relocalising the food chain: the role of creative public procurement. Em: Cardiff University. [2002]. Disponível em:

http://orca.cf.ac.uk/24383/1/RelocalisingProcurement.pdf. Acesso em: 14 dec. 2018.

MORGAN, K.; MORLEY, A. The public plate. Harnessing the power of purchase. Em: MARSDEN, T; MORLEY, A. Sustainable Food Systems Building a New Paradigm. London: Routledge, 2014.

MORGAN, K.; SONNINO, R. The school food revolution: public food and the challenge of sustainable development. London: Earthscan, 2008.

OCHA (2018). Violencia Armada Primer semestre. Em: OCHA. [2018]. Disponível em: https://www.refworld.org.es/pdfid/5ba3df504.pdf Acesso em: 13 dec. 2018.

OLIVEIRA, et al. Comparative assessment of the food purchase program and the national school feeding program's impact in Ubá, Minas Gerais, Brazil. Ciência Rural, Santa Maria, v. 47, n. 1, 2017

PMA. P4P Purchase for Progress - A Primer [2012]. Em: PMA. A P4P Coordination Unit Publication. Disponível em: https://documents.wfp.org/stellent/groups/public/documents/reports/wfp245374.p df. Acesso em: 19 dec. 2018.

PMA. State of School Feeding Worldwide. Em: PMA. Fighting Hunger Worldwide [2013]. Disponível em:

https://documents.wfp.org/stellent/groups/public/documents/communications/wfp 257481.pdf. Acesso em: 19 dec. 2018.

PMA. Abastecimento Alimentar e Compras Públicas no Brasil: Um Resgate Histórico. Em: PMA. Série Políticas Sociais e de Alimentação. [2015]. Disponível em: https://www.mds.gov.br/webarquivos/publicacao/seguranca_alimentar/PAA_Institu cional_Estudo1_Historico_lowres.pdf. Acesso em: 19 dec. 2018.

PNUD. Colombia rural. Razones para la esperanza. Informe Nacional de Desarrollo Humano. Em: PNUD. [2011]. Disponível em: http://www.undp.org/content/dam/colombia/docs/DesarrolloHumano/undp-coic_indh2011-parte1-2011.pdf. Acesso em: 7 jan. 2015.

RIBOT, J.; PELUSO, N. A Theory of Access. Rural Sociology, v. 68, n. 2, p. $153-181$, 2003.

SABATES-WHEELER, R. et al. Building Synergies Between Social Protection and Smallholder Agricultural Policies. Brighton: Future Agricultures Consortium \& Centre for Social Protection, Institute of Development Studies, 2009. 
SÁNCHEZ, J.A. La politica de erradicacion de fumigaciones con glifosato y el "efecto globo". 2005. 85 f. Trabalho de Conclusão de Curso (Ciências Políticas e Relações Internacionais)- Faculdade de Ciências Políticas e Relações Internacionais, Pontificia Universidad Javeriana, Bogotá, 2005.

SIDANER, E. et al. 'The Brazilian School Feeding Programme: an example of an integrated programme in support of Food and Nutrition Security'. Public Health Nutrition, v. 16, n. 6, p. $989-994,2013$.

SILVEIRO, G.; SOUSA, A. Organic foods from family farms in the National School Food Program: Perspectives of social actors from Santa Catarina, Brazil. Rev. Nutr, v. 27, n.3, 2014

SIOBHAN, K.; SWENSSON, L. Leveraging institutional food procurement for linking small farmers to markets. Em: FAO. [2017]. Disponível em: http://www.fao.org/3/ai7636e.pdf. Acesso em: 18 set. 2017.

SUMBERG, J.; SABATES-WHEELER, R. Linking agricultural development to school feeding in sub-Saharan Africa: theoretical perspectives. Food Policy, v. 36, n. 3, p. 341 - 349, 2011.

TELLEZ, S. Informe sobre seguimiento al programa de alimentación escolar -PAEdurante el año 2017 de la procuraduría delegada para la defensa de los derechos de la infancia, la adolescencia y la familia. Em: Procuraduria General de la Nación. Procuraduría Delegada para la Defensa de los Derechos de la Infancia, la Adolescencia y la Familia. [2018]. Disponível em: https://www.procuraduria.gov.co/portal/media/file/180523_Informe-PAE-2017.pdf. Acesso em: 10 dez. 2018.

URIBE, F. El Instituto de Bienestar Familiar. Del asistencialismo paternalista a la participación comunitaria. 1988. Msc., Nova University-CINDE, Medellín, 1988.

WITTMAN, A.; BLESH, J. Food Sovereignty and Fome Zero: Connecting Public Food Procurement Programmes to Sustainable Rural Development in Brazil. Journal of Agrarian Change, v. 17 n. 1, p. 81-105, 2017.

ZAMOSC, L. The Agrarian Question and the Peasant Movement in Colombia. Struggles of the National Peasant Association 1967-1981. Cambridge: Cambridge University Press, 1986. 
Sergio Schneider. Professor Titular do Departamento de Sociologia e membro permanente dos Programas de Pós-Graduação em Desenvolvimento Rural e de Sociologia da Universidade Federal do Rio Grande do Sul. schneide@ufrgs.br

Nathalia Valderrama Bohórquez. Scholar at Doctorate of Rural Development Federal University of Rio Grande do Sul $\neg$ UFRGS/Brazil. Master in Food Science and Technology. Bachelor in Agroindustrial Engineering National University of Colombia UNAL/Colombia.nvalderramabo@unal.edu.co

Como citar: SCHNEIDER, Sergio; BOHÓRQUEZ, Nathalia Valderrama. A aquisição pública de alimentos como mecanismo de desenvolvimento na Colômbia. Redes, Santa Cruz do Sul, v. 24, n. 1 p. 81-105, jan. 2019. ISSN 1982-6745. Disponível em: https://doi.org/10.17058/redes.v24i1.13048. 